\title{
Ad Astra Academy: Using Space Exploration to Promote Student Learning and Motivation in the City of God, Rio de Janeiro, Brazil
}

\section{Wladimir Lyra}

New Mexico State University

wlyra@nmsu.edu

\section{Melissa Rice}

Western Washington University

melissa.rice@wwu.edu

\section{Dhyan Adler-Belendez}

Harvard Graduate School of Education (alumnus) dhyan@alumni.harvard.edu

\section{Neil Jacobson}

University of Southern California

ngjacobs@usc.edu

\section{Ana Pantelic}

University of Belgrade

anapantelic@gmail.com

\author{
Karolina Garcia \\ University of Florida \\ karolina.garcia@ufl.edu
}

\section{Leonardo Sattler Cassara}

Federal University of Rio de Janeiro

leocassara@igeo.ufri.br

\section{Carolyn Crow}

University of Colorado Boulder

carolyn.crow@colorado.edu

\section{Paul Hayne}

University of Colorado Boulder

paul.hayne@lasp.colorado.edu

\author{
Jeffrey Marlow \\ Boston University \\ jjmarlow@bu.edu
}

\section{Keywords}

Astronomy education; Student motivation; Mars exploration; Astrobiology; Outreach for

Development

Motivation is a primary determinant of a student's academic success, but in many under-resourced educational contexts around the world, opportunities to develop motivation are lacking. In the City of God neighborhood of Rio de Janeiro, Brazil, we, a group of scientists and science educators, enacted the Ad Astra Academy, a brief, interactive intervention targeting teenage students at risk of dropping out of school. Students participated in an immersive five-day programme, followed by a six-month lecture series, before completing the second, immersive three-day programme. Participants learned how to use the scientific method in real-world settings to generate new knowledge. In order to consolidate these knowledge gains and bolster the inspirational power of the programme, capstone projects empowered participants to speak with NASA mission managers and, in some cases, acquire never-before-seen images of Mars. While longitudinal study and a more robust sample size are required to bolster conclusions about the efficacy of our approach, initial results suggest that Ad Astra programmes significantly enhance self-efficacy and science-oriented career ambitions.

\section{Introduction}

Among the factors that are positively correlated with academic success, motivation is paramount: with an intrinsic desire to learn, students are better positioned to overcome obstacles and make the most of available opportunities (Linnenbrink-Garcia, 2016). Anecdotal evidence among practising scientists suggests that specific, punctuated events during childhood can spark academic interest and sustain motivation (Heddy \& Sinatra, 2013). The Ad Astra Academy aims to develop such experiences for students in under-resourced educational contexts in order to inspire them to pursue further education, even in the face of structural obstacles. As an organisation led by scientists, it also measures the results of its activities and anal- yses the degree to which focused interventions can have behavioural, academic and career-based effects on participants. Astronomy, astrobiology and space exploration represent compelling subject matter for these efforts because of the sense of wonder, awe, inspiration and other positive emotions that they can instil, especially among youth, and also due to the wide-reaching, universal questions they engage (Valdesolo, 2016). By presenting scientific content in the framework of exploration and discovery, Ad Astra programmes incorporate principles of active learning and team-based projects, placing the student at the center of the learning process and encouraging autonomous learning, thereby providing the opportunity to display resilience, competence and cooperation (Fernandez-Rio, 2017).
Some factors that contribute to student motivation are relatively well-established. Past work has demonstrated the importance of competence, autonomy, and relatedness through the framework of self-determination theory (Deci \& Ryan, 2000), revealing the benefits of metacognition to keep track of progress (Zepeda, 2015) and highlighting the value of a growth mindset in building resilience and sustained academic interest (Dweck, 2016). Similarly, the expectancy-value theory (Wigfield \& Eccles, 2000) has shown that students achievement on a task depends on the subjective value that students assign to it, and whether they expect to succeed.

Most of these and other studies on motivation focus on structural or attitudinal factors; here, we seek to analyse how factors 
such as brevity and intensity of an intervention can lead to long-lasting motivational changes. Simply put: Can a brief, dramatic experience substantially change the nature of a student's motivation, and thereby positively influence their career trajectory? Several authors point to a class of brief interventions that have a long-lasting effect months and even years after they end (Yeager \& Walton, 2011; Walton, 2014). Most of these studies emphasise that longterm effects were detected, but we aim to explore the factors that make this possible. In particular, we are interested in empirically investigating the role that astronomy, astrobiology and space exploration can play in building and sustaining motivation-and in ultimately influencing socio-economic development outcomes.

Here, we present qualitative and exploratory quantitative results from two Ad Astra Academy programmes that spanned four years (2015 and 2018) in the City of God neighborhood of Rio de Janeiro, Brazil. Our after-school programme integrated classroom-based lectures, interactive exercises, full-day field trips outside the city, and immersive Capstone Projects involving active NASA missions. The Ad Astra Academy team included an "international team" (consisting of American and Brazilian scientists and educators who work at US institutions) in conjunction with a "local team" (consisting of Brazilian scientists and educators who work in Rio de Janeiro). The international team brought a breadth of astronomy and astrobiology expertise and direct connections to active NASA exploration missions and the local team fostered effective communication and featured more relatable role models for participating students. While the international and local teams were not identical between 2015 and 2018, the total number of facilitators and the number of English vs Portuguese speakers were the same. We are interested in investigating how the complementary roles of the international and local teams influenced the outcomes of the programmes and student motivation. From the assessment of the implementation and learning outcomes of the Ad Astra Academy programmes, our goal is to identify a set of best practices that can we recommend for implementing brief, intense interventions to enhance student motivation in under-resourced communities.

\section{Motivation and Setting}

The Ad Astra Academy set out to improve the academic experiences of disadvantaged youth through an alternative approach to learning through exploration. In Rio de Janeiro, Brazil, the "favelas" are neighborhoods with high concentrations of people living in poverty, with high levels of criminal activity and limited professional opportunities for young people. It has been shown that, in Brazil, every additional year of education results in a nearly $15 \%$ increase in wages, making education one of the most powerful drivers of economic success (Psacharopoulos \& Patrinos, 2004). However, the unbalanced education system in Brazil means that the poor have few prospects for social mobility, and children growing up in favelas are at a significant disadvantage. Admission rates to the best universities are extremely low, and enrolment is determined by a selection exam that privileges well-resourced students. According to the Brazilian Institute of Geography and Statistics (IBGE), in 2014 the government calculated that $40 \%$ of the students in the top-ranked federal public universities were from the richest quintile of the population, while the poorest quintile represented around $7 \%$ of enrolment (IBGE, 2015). While the situation has improved significantly (from $60 \%$ and $2 \%$, respectively, in 2004), the conclusion is unavoidable: Students from under-resourced communities face major barriers in their pursuit of higher education and social mobility.

In Rio de Janeiro alone, two million favela residents (which accounts for nearly onethird of the city population) are virtually excluded from university-level education. Data from IBGE show that educational trajectories are largely established in secondary school: $30 \%$ of 15 - to 17 -year-olds in the poorest quintile of the population have abandoned school. In contrast, the dropout rate among the richest quintile of the same age range is only $5 \%$ (IBGE).

Social challenges compound the problem. As university and job prospects become unrealized dreams in the favela, other forces take hold. According to 2018 data from the World Health Organization (WHO), Brazil had one of the highest rates of teenage pregnancy in the world (60.8 births per 1000 girls, which was more than six times higher than the rate for high-income countries that are part of the Organisation for Economic Co-operation and Development (OECD)) (WHO, 2018). For boys, the timing of school dropouts coincides with recruitment into drug-related gangs, which target teenagers. According to 2015 Brazilian government statistics, of all arrests made nationwide in Brazil, 18\% were of boys under the age of 18 , and $41 \%$ of these arrests were due to drug-trafficking activities (Brasilia: Presidência da República, 2015).

In short, there are enormous obstacles to professional success for children growing up in the favelas of Rio de Janeiro, and we hypothesize that a strong sense of intrinsic motivation instilled through a brief but exciting intervention could provide positive momentum to help students overcome the circumstances they were born into. The Ad Astra Academy sought to engage students right before the critical age of adolescence when Brazilian teenagers in the City of God are most likely to abandon their education. We partnered with the Instituto Presbiteriano Álvaro Reis (INPAR), a 100-year-old institution that facilitates extra-curricular activities for the youth of the favela ${ }^{1}$. The Ad Astra Academy team also coordinated activities for student participants with the Museum of Astronomy, the City Planetarium, the Museum of Life, and the Valongo Observatory at the Federal University of Rio de Janeiro (UFRJ).

\section{Programme Description}

In collaboration with coordinators at INPAR, we selected cohorts of 20 students between the ages of 12 to 16 years old to participate in each of two programmes in 2015 and 2018. The same criterion was used to choose participants in both years. Initial school-directed selections consisted of the top-performing students (80\% female, $20 \%$ male $)^{2}$; in this context, the programme was presented as a reward for good academic performance. However, in order to fulfill our central aim of engaging students for whom the traditional school system was not working, classes were adjusted to add several boys who were interested in astronomy but were less academically engaged $^{2}$, as these boys face higher risks of being recruited by drug-related gangs. 
This shift resulted in a 50\%-50\% male to female ratio. Both cohorts consisted of heterogeneous groups covering a spectrum of academic interest and susceptibility to dropping out of school. By diversifying the sampling parameters, the Academies were designed to provide a springboard of positive reinforcement for curious students who lacked engaging academic experiences, and also to show students on less productive paths that learning could be an exciting activity with long-term benefits at a key inflection point in their lives.

The curriculum and structure of the programmes were aligned with self-determination theory which specifies the importance of autonomy, competence and relatedness (Deci \& Ryan, 2000). To support student autonomy, we incorporated self-directed learning and viewed learners as active constructors of their knowledge. To support competence, we engaged deeply with content knowledge and procedural knowledge of the scientific method. Finally, to bolster relatedness, we invited local scientists to speak about their research experiences in astronomy and to share their perspectives on how science can work in concert with community goals and values. Details of the programmes (a summary of daily activities, learning objectives and relation to Bloom's Taxonomy of cognition) are provided in Table $1^{5}$ ). The learning and teaching designs for the 2015 and 2018 programmes were similar, although the 2015 programme included two weeks of intense classroom intervention, and the 2018 programme was condensed to a single week

\section{Programme One: 2015}

The inaugural Ad Astra Academy programme in 2015 consisted of two separate sessions: five days in June and three days in November. Prior to the start of any programmatic activities, students were given a pre-test (see "Outcomes" section), administered by INPAR staff. In preparation for the first visit from the international team, INPAR took the students on visits to the Museum of Astronomy and the City Planetarium, both in Rio de Janeiro. These initial activities primed the students for the start of the curriculum with fundamental
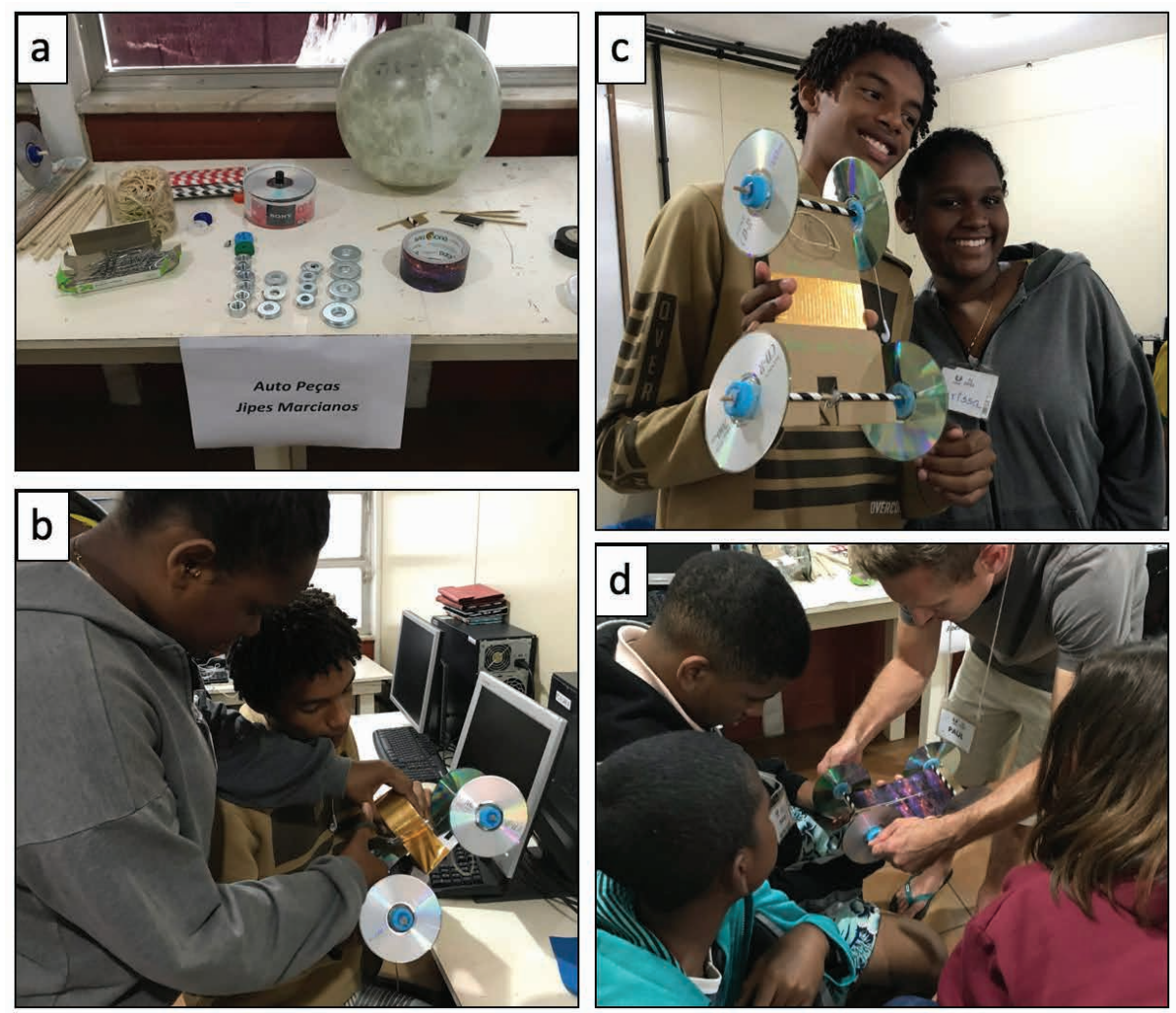

Figure 1. Model Mars rover building activity during the 2018 programme, with starting materials (a) and students assembling rovers in teams together with Ad Astra instructors (b-d). Credit: Ad Astra Academy

knowledge of space-related subject matter and build a sense of excitement for "school not-as-usual."

Two week-long visits from the international team were separated by six months (Table 1). During the first session, the goal was to introduce the students to the process of scientific investigation, to ensure they had an adequate knowledge base to perform the Capstone Project, and to engage the students with the excitement of exploration. This was achieved through a combination of presentations, hands-on activities, and a field trip. While time spent lecturing was generally kept to a minimum, one of the local team members presented an overview of scientists from Brazil who had made significant contributions, showing the students how members of their own community have contributed to important scientific discoveries, thereby making the idea of becoming a scientist more accessible (Brown, 2015).

By positioning a field trip on the second day of the programme, we anticipated positive out-of-classroom team-building effects that would be sustained for the rest of the programme. The field trip during the first session was to Jaguanum Island-a $3 \mathrm{~km}^{2}$ island off the Green Coast of Rio de Janeiro about two hours from the schoolwhich included a trip on a chartered "pirate ship." During the trip, students gained an introduction to field-based science and analysis. The following day, students connected discussions of habitability and life across wide spatial scales, using microscopes and satellite imagery via Google Earth. In the final two days of the first week, students completed activities to prepare them for the Capstone Project, in which teams of students identified sites on Mars where they would request high-resolution images to be acquired from NASA's Mars Reconnaissance Orbiter (MRO) High Resolution Imaging Science Experiment (HiRISE) instrument. Using all they had learned about habitability and geomorphology thus far, student teams provided three scientifically-supported reasons to justify their requests for HiRISE images. In a live video call with HiRISE mission team members at the control centre in Arizona, US, students made their case that the proposed images would provide helpful new information about Mars' past or present conditions. 
Between the first and second visits of the international team, the local team made weekly presentations to the students at INPAR on different topics in astronomy. These events were essential to keep the students engaged and motivated to continue the programme during the next international team visit. In November 2015, the international team reconnected with the students, and, on the first day, ceremoniously revealed large-format posters of the student-requested HiRISE images (Figure 3). (Three of the six requested images were acquired, thanks to the invaluable support of the HiRISE team.) On the second day, the students went on a full-day field trip to the Tijuca Forest, the largest urban forest in the world, to connect themes of habitability, landscape formation processes, and HiRISE images of Mars. On the final day of the programme, student teams used their HiRISE images as a platform for a mock Mars rover mission. Students took turns as "Mission Manager", proposing sites to investigate and types of data to collect. This exercise, which required teamwork skills of negotiation and debate while using well-supported justification, reflected many of the challenges of real-world projects. By requiring a consensus for each round of exploration and ensuring that each student had a turn at the helm, interpersonal dynamics were surprisingly cooperative. At the programme's conclusion, students completed a post-test, identical to the pretest, to enable programme evaluation.

\section{Programme Two: 2018}

Due to time constraints and budget optimisation efforts, the second programme was conducted over a single week in July 2018, allowing us to test a different Capstone Project. The first three days of the curriculum were identical to that of the 2015 programme, building familiarity with the scientific method, highlighting the joy of exploratory field observation, and connecting observations across wide spatial scales using microscopes and satellite imagery.

The Capstone Project, which occupied days four and five, centered around the use of real Mars rover mission data to plan scientific investigations of a Martian crater's habitability and ancient environmental conditions. Rather than generate primary data themselves (as had been done via HiRISE image acquisition in 2015), stu- dents analysed real NASA Mars Science Laboratory (MSL) images and developed science plans based on well-supported hypotheses. They built small model rovers to understand fundamental engineering and design principles (Figure 2), and ultimately pitched their rover traverse plans via videoconference with MSL team members (Figure 3). Unfortunately, due to logistical difficulties, pre- and post-tests were not administered in 2018. As a follow-up to the the five-day programme, the local team returned to INPAR to give a series of presentations over a single week in December 2018.

\section{Outcomes}

\section{Pre- and Post-Tests}

In the 2015 programme, we evaluated outcomes by administering pre- and posttests, which focused on measuring competence, autonomy, and relatedness (Deci \& Ryan; Pugh, 2002). In order to address competence, we measured student knowledge of the scientific method and domain-specific information (e.g. habitability, astrobiology and Mars) before and after participation in the intervention. To address autonomy and relatedness, we measured students' perceptions of science in their community and their perceptions of using and creating scientific knowledge in their community. The test questions and results are summarised in Tables 2-44. Assessments of these areas for 17 participants in the 2015 programme are summarised in the following sections. We note that 17 respondents is a small sample size and presents challenges for producing statistically significant findings; however, as discussed in the following sections, we have confidence in several results (those with $p$-values $<0.05$ are considered statistically significant).

\section{Competence I: Scientific Method}

We summed the number of correct responses on the pre- and post-tests (Table 2), creating a single score which ranged from 0 to 9 with higher scores indicating more correct answers. Results of a paired samples t-test indicated that students had significantly higher scores on the scientific method related questions at post-test $(\mathrm{M}=7.06, \mathrm{SD}=1.06)$ compared to pre-test $((M=4.25, S D=1.12): t(15)=-9.63, p$
$<$.001). Students began the study unsure of what data, experimental control, and a hypothesis were, with correct response rates below $24 \%$. Post-test scores showed that students made gains in all areas, although understanding what a hypothesis is proved difficult for students both before and after the programme.

Additionally, we coded student responses to short-answer questions about what the scientific method is, how it could be used to study a local phenomenon, and how one might redesign an experiment to more accurately address a target question. Answers were coded by two researchers for keywords identified by a domain expert with inter-rater agreement above $90 \%$. While students incorporated more keywords in their responses at post compared to pre, the only significant difference emerged for redesign of an experiment. At pre-test, student responses averaged less than one scientific keyword whereas posttest responses averaged more than one keyword.

\section{Competence II: Mars}

We summed the number of correct responses to questions about Mars (Table 3 ), creating a sum score ranging from 0 to 3 , with higher scores indicating more correct answers. Overall, students answered significantly more questions correctly at post $(M=1.87)$ compared to pre-test $((\mathrm{M}=.68): \mathrm{t}(15)=-7.25, p<.001)$. Most notably, students' understanding of what a habitat needs to sustain life benefitted from the intervention. This is reinforced by short-answer responses to the question: "What would a human need to survive on Mars?". While students exhibited knowledge gains about Mars overall, they struggled on questions pertaining to environmental conditions, such as explaining the planet's red color. Overall, despite difficulty with specific content, students increased their knowledge of Mars and also provided more well-reasoned arguments that life beyond Earth may be possible.

\section{Autonomy and Relatedness}

We were also interested in how students perceived the role of science for themselves and their community. We created a measure based on eleven questions that asked students to reflect on their role in conducting science and producing sci- 

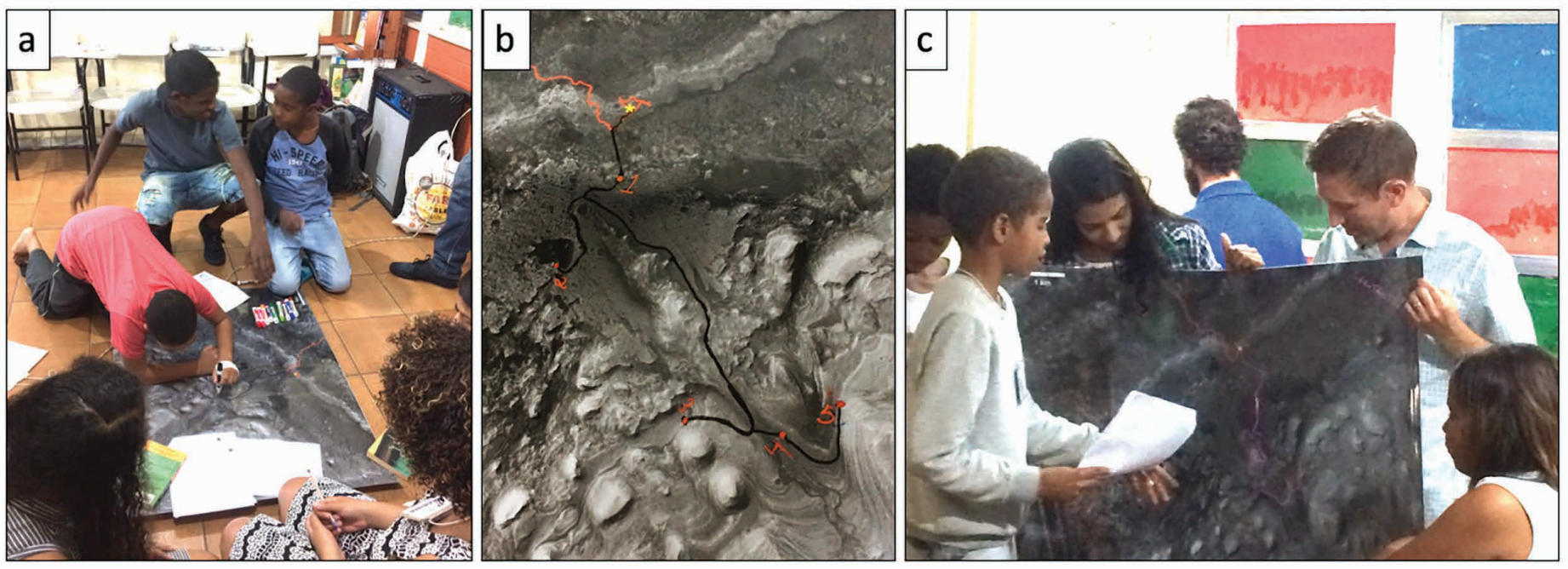

Figure 2. Ad Astra Academy Capstone Project from the 2018 programme: (a) students study a HiRISE image of the MSL Curiosity Rover's landing site in Gale Crater, Mars, (b) traverse locations selected by students on Mt. Sharp in Gale Crater (yellow star indicates the rover's location at the time of the July 2018 programme); (c) students present their future traverse proposals and science rationales to MSL team members via Skype. Credit: Ad Astra Academy

entific knowledge (Table 4). Three of the items were reverse coded so that the direction of all effects could be viewed positively. This resulted in a measure with a minimum of 1 indicating strong disagreement, and 6 indicating strong agreement. Overall, the results indicated a significant increase in students' perceptions of their ability to contribute to scientific knowledge and the ability of science to solve problems from the pre-test $(M=3.68)$ to the post-test $((M=5.46): t(10)=-3.72, p=$ .004). Responses for five of the eleven items on the pre-test were below the midpoint of the scale, indicating that students disagreed with statements including, "I am a scientist", "Science can solve any problem" and "In the future, I want to be a scientist", all of which became significantly ( $p$ values $<.03$ ) above the midpoint after completing the programme.

Additionally, an intriguing pattern emerged for the relationship between the role of one's self in science and the role of science in one's community. While students' belief in their ability to carry out their own experiments and to use science to help their community increased, students actually decreased, although not significantly ( $p=$ .18), in the belief that their community uses science to solve problems. One possible explanation of this decrease is that after gaining first-hand experience of the rigour and limitations of the scientific method, students' confidence in their community's problem-solving science decreased.
However, the validity and implications of this potential link require further targeted study.

\section{Student Experiences}

Developing a quantitative understanding of how the intervention may have changed participants' educational paths and career prospects will require several additional years of longitudinal tracking. Nonetheless, individual testimonials and progression through academic milestones suggest that, for a subset of participants, the programme was a transformative event. Several students said that the experience revealed novel ways of viewing and interacting with the natural world. "[The programme] changed my way of thinking," explained one participant, who declared her newfound desire to be an astronomer, "Now, when I walk in the street, I look at the sky." The same student also said that she always liked "the stars and the planets", but she did not know that "something like this could be a profession."

Two of the particularly "at-risk" students noticed a shift in their mindsets toward more active inquiry and enhanced personal agency. "I did not realise that when I'm on a beach, that I can pick things up, collect data and learn more," said one. Another noted that "the project made me think more like this: look at the world around me, and ask several questions."
Another participant is studying for college entrance exams and hopes to pursue a STEM career. She pointed to the Capstone Project as a key motivator, and the overall experience as a memory she would call upon during future struggles. "We took a picture of Mars that no one ever saw or understood," she explained, "and we will be the first people to see it, and I feel a bit special... this project is very important to me; I will never forget this week." This student also benefited from the team's gender diversity: "I was even more motivated because I had a certain fear of being the only woman among the biologists and such, but when I saw other scientists who were women, it encouraged me."

Most striking across the post-programme interviews was the power of new physical experiences to shift students' mindsets. From riding on a boat for the first time, to seeing a jellyfish, observing plankton under a microscope, controlling an underwater robot, and seeing Saturn through a telescope, the density of new experiences created a sense of novelty and excitement that is now associated with curiosity, learning and empowerment.

After 2015, the only INPAR students who pursued any form of higher-education were from the Ad Astra cohort. Of the 20 students who participated in the 2015 programme, two have gone to college, one graduated from a higher-education teaching programme, and another is currently 
taking pre-college preparatory courses and exams. While we have insufficient data to attribute these students' decisions directly to their participation in Ad Astra Academy, we plan to follow students from the 2018 programme and future iterations of Ad Astra Academy as well, and will compare to control groups of other INPAR students to assess the long-term impacts of the intervention.

\section{Instructor Best Practices}

The strategically designed curricula described above and in Table 1 offer a path for students to gain fluency in performing scientific investigations and learn a great deal about habitability, astrobiology and Mars. However, we believe that confidence-building, attitude-based outcomes are equally important for student success. In this spirit, we developed recommendations for best practices on the key features that make Ad Astra Academy unique throughout both programmes: a passion for learning through experience and exploration, empowerment through inquiry and resilience, and promotion of curiosity and critical thinking. In practice, these goals translated into a few actionable guideposts for all instructors:

1. Consistently remind/encourage students to write or sketch observations in lab notebooks.

2. Encourage students to ask questions at all times, through any mode possible (e.g. verbally or in writing).

3. Lead students along paths of inquiry. If a student's question can be tested, ask guiding questions that direct them to formulate experiments. Prioritise the enactment of these experiments over standard curriculum activities when possible and appropriate.

Convey the range of emotions that come with being a scientist, from the challenges of failed experiments to the joy of solving a hard problem, and contributing new knowledge to the world.

\section{Other Deliverables and Impacts}

\section{Spacecraft Images}

Based on student requests and scientific reasoning, three high-resolution images

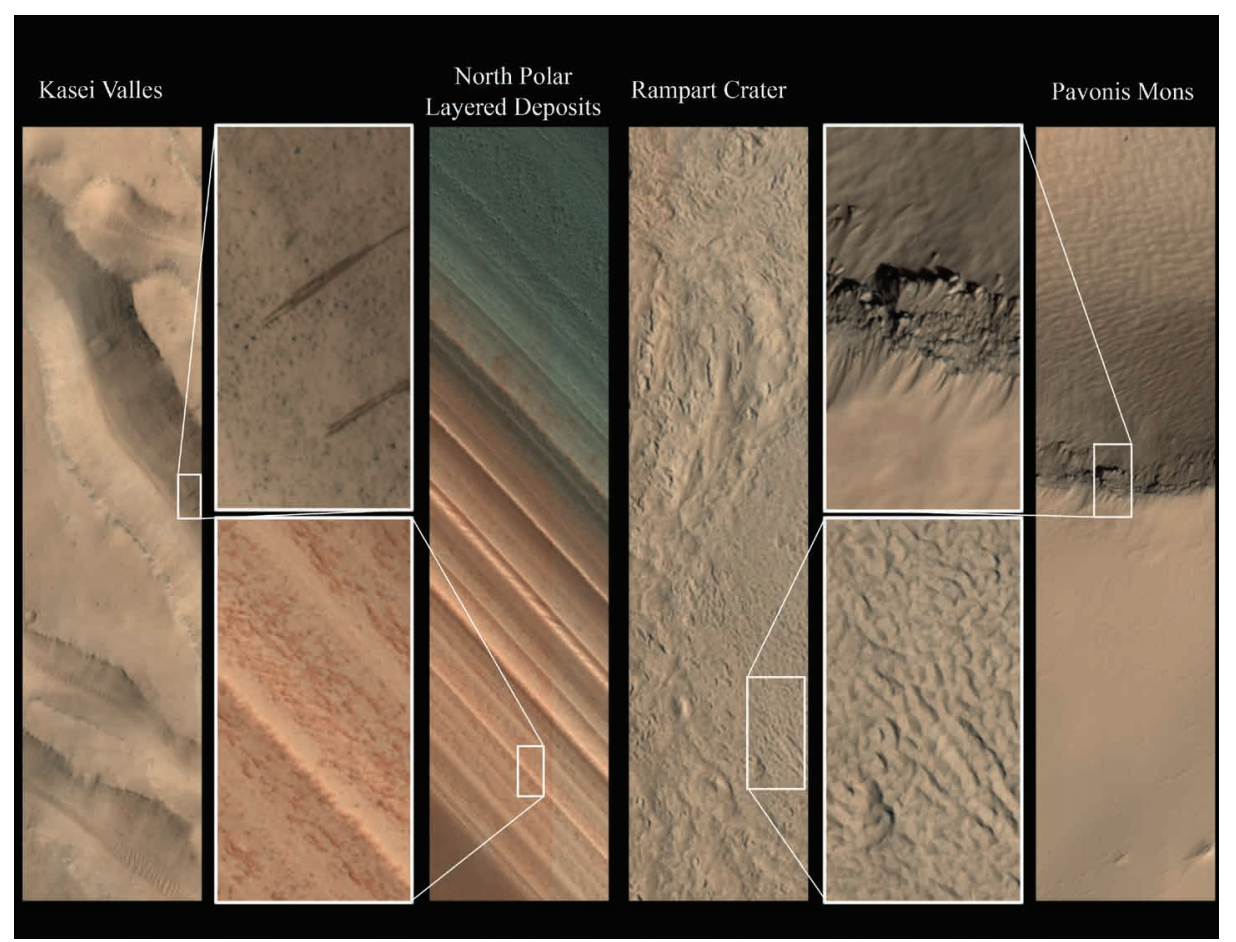

Figure 3. Highlights from the four HiRISE images acquired by the 2015 Ad Astra Academy participants. Inset images show particular areas of interest, including slope streaks at Kasei Valles, dunes of various scales near the north pole, deformed terrain at a putative rampart crater, and a pronounced rock outcrop on Pavonis Mons. Credit: NASA/JPL/University of Arizona

(Figure 3) were acquired by the HiRISE team of: Kasei Valles, the North Polar Layered Deposits, a crater in the mid-latitudes, and the Pavonis Mons volcano 5 . In Kasei Valles, dark slope streaks were observed along channel walls, indicating relatively recent wet or dry flows. At the North Polar Layered Deposits, distinct mixtures of ice and soil form metre- to decametre-scale layers, offering clues to past climatic regimes. The mid-latitude rampart crater was surrounded by broad, rounded shapes, suggesting that the impact may have melted subsurface ice and led to fast-flowing fluidised ejecta. On the northern flank of the Pavonis Mons volcano, three distinct rock outcrops punctuate otherwise flat terrain, whose dunes could help inform atmospheric circulation.

These images would not have been acquired without the partnership between the Ad Astra Academy's student explorers and the HiRISE mission's education and outreach team. We anticipate that the images will be incorporated by the broader research community into existing and future studies, ensuring a substantive student contribution to Mars exploration.

\section{Scholarships}

To further the impact of the 2018 programme, we selected two students, aged 16 and 17, for scholarships in partnership with the Museum of Life, in Rio de Janeiro. The students go to the Museum twice a week, participating in their experimental and educational activities. They receive remuneration commensurable with the minimum wage in Brazil. The intent of providing a paid opportunity is to retain them in science and pursuit of college by alleviating the financial pressure that would make them pursue a non-academic minimum wage job with little intellectual stimulation.

\section{Discussion}

The exploratory quantitative analysis and anecdotal data presented in preceding sections point to significant positive changes in competence, autonomy and relatedness, as well as more substantial effects on certain students' career objectives and worldviews. 
Several challenges-both anticipated and unforeseen-complicated the programme's implementation and may have prevented educational gains from reaching their full potential. As expected given the inclusion of students with poor attendance and behavioural records, disruptive behavior was occasionally distracting. Teaching via translators was a slow process that, at times, limited information transfer and hindered deeper connections between students and international instructors. Teacher training efforts were limited to an information-sharing session and did not allow Ad Astra Academy leaders to observe local teachers' incorporation of key programmatic elements (e.g. active learning, student-directed inquiry, exploration of the natural world) into subsequent classroom activities.

Given our analysis of the pre- and posttests; interviews with students, teachers, and family members; and Ad Astra Academy team member reflections, future programmes will prioritize several additions and modifications. The telescope night event was an encouraging sign of community interest; enhancing this component by providing students with a platform to share their new knowledge and show the confidence they have attained will build longerterm buy-in from potentially sceptical family members or community leaders. While we hope Ad Astra Academy programmes instil a long-lasting passion for learning in the students themselves, engagement from the students' families is a critical piece of the puzzle. Family member interviews revealed that caregivers almost universally see higher education as a worthy pursuit, but in the face of challenging economic circumstances, income-generating activities take priority. We anticipate that involving caregivers in the student's journey of discovery and curiosity-in addition to the scholarships Ad Astra Academy offers-will lead to a stronger commitment to the long-term benefits of education.

One of the most effective ways to consolidate knowledge gains and develop a deeper understanding of relevant principles is through project-based activities (Kanter, 2010). Our curriculum included several short-term projects, but students would likely benefit from more sustained and self-directed efforts. For example, developing a research agenda to follow up on questions that arose during the week would nurture a seed of interest. With the tools of the scientific method at their disposal, motivated students would be well positioned to expand their knowledge base.

Other tweaks to the programme will help align our efforts with published best practices. For example, by highlighting the struggles of the international scientists, we can remove the stigma of uncertainty, eliminate the misconception of "innate talent," and facilitate a growth mindset (Lin-Siegler, 2016). Asking students to reflect on daily activities and the programme's broader lessons in a more private, personal context (e.g. through journaling) will help participants gain ownership of the material and tailor it to their specific circumstances (Zepeda, 2015; Brown, 2015).

Modifications to our team composition and classroom approach would ease the language barrier issues and make the best use of limited time. In both iterations of the Brazil academies, the international team consisted exclusively of scientists; involving trained educators (as has occurred at other Ad Astra Academies around the world) would be helpful in building cohesion and limiting disruptions through classroom management and team-building exercises. Working with translator scientists was an essential yet surprisingly effective part of the process. At their best, the translators who were scientists understood the learning objectives of a given activity and guided groups of students down the path of discovery. This independence saved time by avoiding word-for-word translation and improved knowledge delivery by incorporating culturally-relevant references. To enhance these effects, future programmes will involve local scientists from an earlier stage of curriculum development to ensure all instructors buy in to the programme's underlying objectives and understand the curriculum's progression to attain them.

Local scientists provided a bridge not only in terms of language, but also in their relatability: students could "see themselves" more easily in the local scientists than in the international team members. Given the strong effects of representation in building self-efficacy (Morgenroth, 2015), bolstering this component by involving role models as close to the students' cultural, social, and economic circumstances as possible is a priority. Nonetheless, we also found that including international scientists provided some unexpected benefits. The range of domain-specific expertise encompassed by the team meant that a broad set of student questions could be answered. Instructors' deep knowledge of experimental design allowed them to quickly arrange demonstrations or experiments to address questions and provide positive reinforcement to curious students. In addition, the "eventised" nature of incorporating international scientists made students feel valued, special, and part of something important. In the 2015 iteration, several participants expressed skepticism that the team would in fact return after the first week of instruction or that HiRISE images would be acquired. Demonstrating that scientists from outside the City of God-a traditionally marginalised community-care about students' difficulties and aspirations may provide an emotional boost as important as the intellectual one (Theron, 2012). As one student explained, "When they told me that this project would come to Brazil, I did not really believe it. I do not trust anyone saying they will come here-for me, it is not a possible thing. But when I saw them here, I was like, 'Ah, it's true!' I was so surprised." Another reported, "When I saw the [HiRISE] pictures, I felt, 'Whoa, they said they were going to send them, and they really did bring them back!' It gave me great joy. We made the photo analysis and have seen some important things."

In order to scale the core tenets of Ad Astra Academy's pedagogical approach-experiential, inquiry-based learning through the lens of exploration-disseminating these principles through local teachers is essential. After all, teachers have more sustained contact with students and their families and are better positioned to tailor instructional approaches to an individual pupil's interests and life circumstances. A more extensive teacher training programme that allows time for practise and feedback for both the international Ad Astra Academy team and local teachers would be a productive next step.

Many of our future course corrections seek to build a culture of knowledge and exploration around Ad Astra Academy students. Our initial evidence suggests that, for many participants, the spark of inspiration caught hold, but it needs fuel-in 
the form of family support, longer-term projects that reinforce key principles, and classroom environments that promote student inquiry - to continue burning. While developing a full infrastructure of support is beyond the scope of our programme, the relatively straightforward modifications highlighted above will help capitalise on the knowledge, attitude and behavior gains students attain from the punctuated Ad Astra Academy experience.

\section{Conclusions}

Ad Astra Academy programmes in Brazil have sought to instil a passion for knowledge and exploration in under-resourced communities among students with limited educational and economic opportunities. Through brief, interactive interventions designed to empower students to contribute to the leading edge of space exploration, many students reported transformational impacts. Analysis of preand post-tests indicated that participants expressed a markedly enhanced ability and desire to engage in scientific research following the programme. Substantial methodological challenges for the study remain, including the collection of longterm data to evaluate the programme's impact on career success. Nonetheless, we are encouraged by the initial results presented here, which support our hypothesis that brief, impactful interventions can play a positive role in a student's educational trajectory through enhanced autonomy and self-efficacy.

\section{References}

'Mapa do encarceramento: os jovens do Brasil / Secretaria-Geral da Presidência da República e Secretaria Nacional de Juventude', Brasília: Presidência da República, 2015, https://nacoesunidas.org/ wp-content/uploads/2018/01/Mapa do Encarceramento - Os_jovens_do_brasil. pdf

Brown, E.R., J.L. Smith, D.B. Thoman, J.M. Allen, and G. Muragishi,'From bench to bedside: A communal utility value intervention to enhance students' biomedical science motivation,' Journal of Educational Psychology, vol. 107 , no. 4, 2015, p. 1116
Deci, E., and R. Ryan, 'The "What" and "Why" of Goal Pursuits: Human Needs and the Self-Determination of Behavior', Psychological Inquiry. vol. 11, 2000, p. 227268, doi: 10.1207/S15327965PLI1104_01

Dweck, C.S., 'Mindset: the New Psychology of Success (updated edition)', Ballantine Books: New York City, 2016

Fernandez-Rio, J., N. Sanz, J. FernandezCando and L. Santos, 'Impact of a sustained Cooperative Learning intervention on student motivation', Physical Education and Sport Pedagogy, vol. 22, no. 1, 2015, p. 89-105, doi: 10.1080/17408989.2015.1123238

Heddy, B. C., and G. M. Sinatra,'Transforming Misconceptions: Using Transformative Experience to Promote Positive Affect and Conceptual Change in Students Learning About Biological Evolution', Science Education, vol. 97, no. 5, 2013, p. 723-744, doi:10.1002/sce. 21072

Instituto Brasileiro de Geografia e Estatística (IBGE), 'Síntese de Indicadores Sociais 2015', uma análise das condições de vida da população brasileira [online], Rio de Janeiro, 2015, http://biblioteca.ibge.gov.br/ visualizacao/ livros/liv95011.pdf

Kanter, D.E., 'Doing the Project and Learning the Content: Designing Project-Based Science Curricula for Meaningful Understanding,' Science Education, vol. 94, no. 3,2010 , p. 525-551

Linnenbrink-Garcia, L., E.A. Patall, and R. Pekrun, 'Adaptive Motivation and Emotion in Education', Policy Insights from the Behavioral and Brain Sciences, vol. 3, no. 2 , 2016, p. 228-236, doi:10.1177/2372732216644450

Lin-Siegler, X., J.N. Ahn, J. Chen, F.F.A. Fang, and M. Luna-Lucero, 'Even Einstein struggled: Effects of learning about great scientists' struggles on high school students' motivation to learn science,' Journal of Educational Psychology, vol. 108, no. 3, 2016, p. 314

Morgenroth, T., M.K. Ryan, and K. Peters, 'The Motivational Theory of Role Modeling: How Role Models Influence Role Aspirants' Goals,' Review of General Psychology, vol. 19 no. 4, 2015, p. 465-83

Psacharopoulos, G., and H.A. Patrinos, 'Returns to Investment in Education: A Further Update', Education Economics, vol.12, no.2, 2004, p. 111-134

Pugh, K.,'Teaching for Transformative Experiences in Science: An Investigation of the Effectiveness of Two Instructional Elements', Teachers College Record, vol. 104, no. 6,2002 , p. 1101-37
Theron, L., P. Engelbrecht, and M. Ungar, 'Caring Teachers: Teacher-Youth Transactions to Promote Resilience,' The Social Ecology of Resilience: A Handbook of Theory and Practice, NY: Springer New York,New York, 2012, p. 265-280

Valdesolo, P., A. Shtulman, and A.S Baron,'Science is awe-some: The emotional antecedents of science learning', Emotion Review, 2016

Walton, G.M.,'The New Science of Wise Psychological Interventions.' Current Directions in Psychological Science, vol. 23 no. 1,2014 , p. $73-82$

'World health statistics 2018: monitoring health for the SDGs, sustainable development goals,' World Health Organization, [online] Geneva, 2018, Licence: CC BY-NC-SA 3.0 IGO https://apps.who.int/iris/bitstream/han dle/10665/272596/9789241565585-eng. pdf?ua $=1$

Wigfield, A., and J.S. Eccles, 'Expectancyvalue theory of achievement motivation', Contemporary Educational Psychology, no. 25, vol. 1, 2000, p. 68-81, doi:10.1006/ ceps.1999.1015

Yeager, D.S. and G.M. Walton, 'Socialpsychological interventions in education: They're not magic,' Review of Educational Research, vol. 81, 2011, p. 267-301

Zepeda, C.D., J.E. Richey, P. Ronevich, and T.J. Nokes-Malach, 'Direct instruction of metacognition benefits adolescent science learning, transfer, and motivation: An in vivo study', Journal of Educational Psychology, vol. 107, no. 4, 2015, p. 954-970

\section{Notes}

There are many NGOs acting in the favelas, though most are related to sports or arts. Ad Astra Academy is one of the first science-focused programmes operating in the favelas.

2 In the 2015 report from the Instituto Brasileiro de Geografia e Estatística in the references document shows that of those who completed secondary education, $55 \%$ were men and $67 \%$ were women in the whole country. When broken down by race, there was a $12 \%$ gap in favor of women wides to $19 \%$ when only people of darker skin tone are considered. This government report that this may be due to societal gender norms that direct boys into the workforce at an early age, making them manage both work and study. This is potentially the reason for the disparity in the school-directed selections.

3 Academic engagement was based on school attendance, performance, and motivation. 
4 Tables 1, 2, 3 and 4 are available online at the CAPjournal website: www.capjournal.org

5 The images have the following IDs: Kasei Valles (image ID ESP_043797_2070), the North Polar Layered Deposits (image ID ESP 042748 2650), a crater in the mid-latitudes (image ID ESP_042536_2170), and the Pavonis Mons volcano (image ID ESP_052317_1830).

\section{Acknowledgements}

We dedicate this manuscript to Loloano Claudionor da Silva, a Brazilian scientist and indispensable Ad Astra Academy local team leader, who passed away unexpectedly in January 2019. We will miss him greatly as we continue the work that he cared so deeply about, as will the many students who have been inspired by his kindness, humor and passion for learning. Ad Astra Academy thanks the following sources of funding that have made the Brazil programmes possible: the International Astronomical Union, Rolex, and the National Geographic Society. We thank Hank Leukart, Alejandra Frias, and Julia DeMarines for their contributions as Ad Astra team members. We thank Liliane Mynssen and the entire INPAR staff including the students who participated in the
Ad Astra Academies, GalileoMobile, Rio de Janeiro's Museum of Astronomy, Rio de Janeiro's City Planetarium, the NGO Parceiros da Educação, Patricia Spinelli, Sandra Benitez Herrera, João Paulo Nogueira Cavalcante, Raquel Boesso Silva, Leandro Guedes, Wailã de Souza Cruz, Flavia Lima, Alexandre Cherman, Daniel Mello, and Silvia Lorenz. Finally, we also thank the MRO HiRISE team and MSL team members Vandi Verma, Matt Heverley, Katie Stack Morgan and Abigail Fraeman.

\section{Biographies}

Wladimir Lyra is an Assistant Professor of Astronomy at New Mexico State University and Brazil Site Director of the Ad Astra Academy.

Melissa Rice is an Associate Professor of Planetary Science at Western Washington University. She is a science team member of the NASA Mars Science Laboratory and Mars2020 Rover missions.

Dhyan Adler-Belendez received his Master's degree from the Harvard Graduate School of Education. His work focuses on improving mathematics and science education.
Neil Jacobson is a PhD candidate at the University of Southern California's Rossier School of Education. His work investigates the conceptual change process as it applies to scientific, social, historical, and political knowledge.

Ana Pantelic is a social entrepreneur and international development professional with a decade of experience working at the intersection of systems change, social innovation, and economic opportunity.

Karolina Garcia is a PhD candidate in astronomy at the University of Florida, studying galaxy clusters and supernovae.

Leonardo Sattler Cassara is an astrophysicist currently working as a Research Assistant at the Federal University of Rio de Janeiro.

Carolyn Crow is a Planetary Scientist and Cosmochemistry in the Department of Geosciences at the University of Colorado Boulder and the Program Director for the Ad Astra Academy.

Paul Hayne is an assistant professor of astrophysical and planetary sciences at the University of Colorado Boulder, and is Science Director for the Ad Astra Academy.

Jeffrey Marlow is an Assistant Professor of Biology at Boston University and the Executive Director of the Ad Astra Academy.

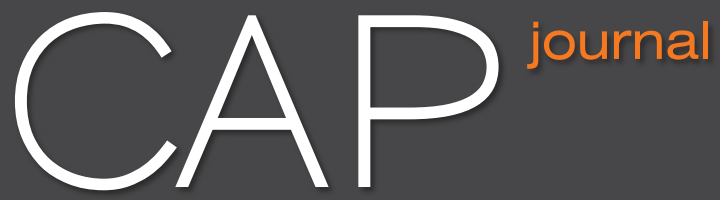

Communicating Astronomy with the Public

\section{Dear Readers,}

Please contribute to improving CAP journal, by filling in our short questionnaire at:

https://www.capjournal.org/survey.php

We welcome your feedback!

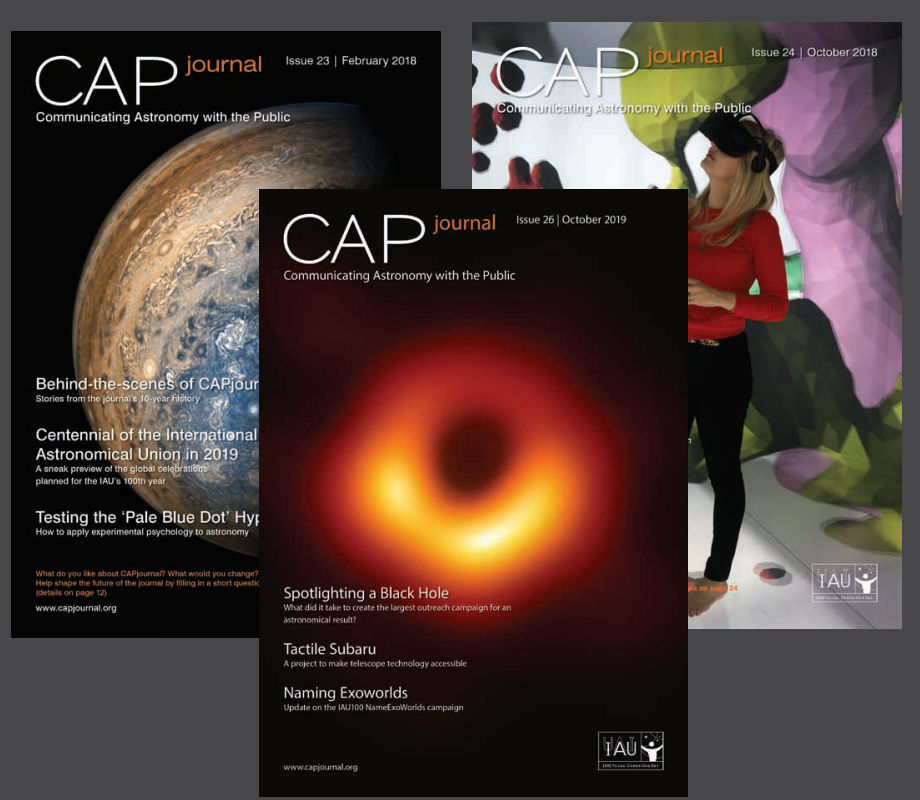

